\title{
AVALIAÇÃO in vitro DA ATIVIDADE DA SUBFRAÇÂO E SUBSTÂNCIA OBTIDAS DAS RAÍZES DE Cochlospermum regium EM BACTÉRIAS CAUSADORAS DE INFECÇÕES NOSOCOMIAIS.
}

\author{
C. Magalhães, Jaqueline M. S. Ferreira \\ Universidade Federal de João Del Rei (UFSJ), Divinópolis/MG. \\ e-mail:julianapalumbo@yahoo.com.br
}

Juliana M. C. Palumbo, Rafaella S. Carvalho, João M. Siqueira, José

\section{Resumo}

A prevalência de microorganismos multirresistentes tem aumentado em infecções nosocomiais. Diante disso, a prospecção de novos antimicrobianos de origem natural representa uma importante alternativa no combate a estas infecções. Portanto, o objetivo deste trabalho foi avaliar a atividade bacteriostática in vitro do extrato hidroetanólico e da fração acetato de etila (AcOEt) de Cochlospermum regium contra três bactérias Gram negativas Klebsiella pneumoniae (ATCC 27.736), Acinetobacter baumannii (ATCC 19.606) e Pseudomonas aeruginosa (ATCC 25.619) e quatro bactérias Gram positivas Staphylococcus aureus (ATCC 29.213), Staphylococcus epidermidis (ATCC 12.228), Streptococcus agalactiae (ATCC 13.813) e Staphylococcus mutans (ATCC 25.175). A espécie C. Regium, popularmente conhecida como "algodãozinho", sendo utilizada na medicina popular nos estados de GO, MT, MS, DF, SP e MG. A concentração inibitória mínima (CIM) foi determinada através da técnica de microdiluição em caldo, como descrito no Clinical and Laboratory Standards Institute (CLSI, 2003), com algumas modificações. As linhagens microbianas previamente cultivadas em ágar nutriente tiveram suas densidades ajustadas com solução salina à turbidez da escala 0,5 de McFarland. O extrato hidroetanólico e a fração AcOEt foram diluídos em série em concentrações que variaram de 1000 a 31,25 $\mu \mathrm{g} / \mathrm{mL}$ em dimetilsufóxido (DMSO 20\%). A Estreptomicina $100 \mu \mathrm{g} / \mathrm{mL}$ foi utilizada como controle positivo e o DMSO $20 \%$ como controle negativo. O extrato hidroetanólico apresentou atividade frente às bactérias Gram negativas $P$. aeruginosa e $A$. baumannii com CIM de $125 \mu \mathrm{g} / \mathrm{mL}$, enquanto a $S$. epidermidis e a $S$. mutans apresentaram CIM com valores de $62,5 \mu \mathrm{g} / \mathrm{mL}$. A fração AcOEt foi ativa contra todas as bactérias analisadas, com CIM de $125 \mu \mathrm{g} / \mathrm{mL}$ frente $P$. aeruginosa e A. baumannii, $250 \mu \mathrm{g} / \mathrm{mL}$ em relação a $S$. epidermidis e CIM de $62,5 \mu \mathrm{g} / \mathrm{mL}$ frente a $S$. mutans. Os resultados mostraram que $C$. regium tem uma potencial atividade antibacteriana e os resultados obtidos estimulam estudos posteriores a fim de isolar e caracterizar os compostos bioativos presentes nesta planta com propriedades antimicrobianas. 
Palavras-chave: algodãozinho, extrato hidroetanólico e fração acetato de etila.

Apoio financeiro: CNPq, FAPEMIG, UFSJ 